\title{
High-Dose Neutron Irradiation of Hi-Nicalon Type S Silicon Carbide Composites Part 2: Mechanical and Physical Properties
}

\author{
Yutai Katoh, ${ }^{1}$ Takashi Nozawa, ${ }^{2}$ Chunghao Shih, ${ }^{1}$ Kazumi Ozawa, ${ }^{2}$ Takaaki Koyanagi, ${ }^{1}$ \\ Wally Porter, ${ }^{1}$ Lance L. Snead ${ }^{1}$ \\ ${ }^{1}$ Oak Ridge National Laboratory, Oak Ridge, Tennessee, USA \\ 2 Japan Atomic Energy Agency, Rokkasho, Aomori-ken, Japan
}

*Corresponding author address: Oak Ridge National Laboratory, PO Box 2008 MS6138, Oak Ridge TN, 37831-6138, USA. Tel.: 1-834-576-5996. E-mail: katohy@ornl.gov.

\begin{abstract}
Nuclear-grade silicon carbide ( $\mathrm{SiC}$ ) composite material was examined for mechanical and thermophysical properties following high-dose neutron irradiation in the High Flux Isotope Reactor at a temperature range of 573-1073 K. The material was chemical vaporinfiltrated SiC-matrix composite with a two-dimensional satin weave Hi-Nicalon Type S SiC fiber reinforcement and a multilayered pyrocarbon/SiC interphase. Moderate $(1073 \mathrm{~K})$ to very severe $(573 \mathrm{~K})$ degradation in mechanical properties was found after irradiation to $>70 \mathrm{dpa}$, whereas no evidence was found for progressive evolution in swelling and thermal conductivity. The swelling was found to recover upon annealing beyond the irradiation temperature, indicating the irradiation temperature, but only to a limited extent. The observed strength degradation is attributed primarily to fiber damage for all irradiation temperatures, particularly a combination of severe fiber degradation and likely interphase damage at relatively low irradiation temperatures.
\end{abstract}

\section{Introduction}

Taking advantage of the outstanding radiation tolerance of silicon carbide $(\mathrm{SiC})$ in fully crystallized and stoichiometric forms [1-3], continuous SiC fiber-reinforced SiC-matrix ceramic composites have been developed for nuclear fusion [4-6] and fission applications [7-9]. Presently, ceramic composites with Generation III SiC fibers [10] such as Hi-Nicalon ${ }^{\text {TM }}$ Type S (NGS Advanced Fibers Co., Ltd., Toyama, Japan) and Tyranno ${ }^{\mathrm{TM}}$ SA3 (Ube Industries, Ube, Japan) and crystalline $\mathrm{SiC}$ matrices made through the chemical vapor infiltration (CVI) [11] or nano-infiltration and transient eutectic-phase [12] processes have proved to survive low- to medium-dose neutron irradiation without significant detrimental effects $[13,14]$ except an inherently inevitable decrease in thermal conductivity. Among these radiation-tolerant "nuclear-grade" SiC composites, the Hi-Nicalon Type S fiber, CVI SiCmatrix composite was the first developed and is considered a reference nuclear-grade material.

Tracing the history of nuclear-grade $\mathrm{SiC}$ composites, the earliest-generation materials were first reported to be stable at a displacement damage level of 1 dpa by Snead et al. [15], despite the fact that previous non-nuclear-grade composites exhibited major degradation 
below that dose level [16]. Follow-up neutron irradiation experiments published by various authors in the United States, Japan, and Europe confirmed that the radiation stability was maintained well beyond $1 \mathrm{dpa}$, up to the order of $10 \mathrm{dpa}$, in a broad temperature range of 573 to $1573 \mathrm{~K}[13,17-22]$. However, data on neutron irradiation effects in nuclear-grade SiC composites at higher doses beyond 10 dpa have been very scarce and limited to those from one experiment in the High Flux Isotope Reactor (HFIR) at Oak Ridge National Laboratory (ORNL). From that experiment, Katoh et al. reported no significant effects of irradiation to $\sim 41 \mathrm{dpa}$ at $1073 \mathrm{~K}$ on the flexural properties-including strength, proportional limit stress (PLS), and Young's modulus - of a Hi-Nicalon Type S, CVI SiC-matrix composite [23].

This paper reports details of the physical, thermal, and mechanical properties of the HiNicalon Type S, CVI SiC-matrix composite following neutron irradiation in HFIR to high doses of up to $\sim 74 \mathrm{dpa}$ at a temperature range of 573-1073 K. Note that the materials represent the very first generation of the nuclear-grade $\mathrm{SiC}$ composite that had not necessarily been optimized for balanced properties. In particular, the first pyrocarbon (PyC) layer in the $\mathrm{PyC} / \mathrm{SiC}$ multilayer interphase in this material is considered significantly too thin to achieve adequate toughness for this particular composite system [24, 25]. Moreover, among the Generation III commercial SiC fibers, the nanocrystalline structure of Hi-Nicalon Type S fiber is not expected to be the most stable under irradiation. In the companion paper, Perez-Bergquist et al. identified a significant microstructural modification in the multilayer interphase, a suspected instability issue for Hi-Nicalon Type $\mathrm{S}$ fiber, and associated interface debonding mainly at the irradiation temperature of $573 \mathrm{~K}$ [26].

\section{Experimental Procedures}

The material evaluated was an $\mathrm{SiC}$ fiber, $\mathrm{SiC}$-matrix composite with a two-dimensional (2-D) 8-harness satin-weave Hi-Nicalon Type S (lot number 2D2685-02-I5-01, year 2000) reinforcement in a $0^{\circ} / 90^{\circ}$ stacking configuration and a CVI SiC matrix. A multilayer interphase consisting of $5 \times\left(\mathrm{PyC}_{\sim 20 \mathrm{~nm}} / \mathrm{SiC}_{\sim 100 \mathrm{~nm}}\right)$ was applied as a chemical vapordeposited coating onto an untreated fiber surface (but with the sizing material removed) before the matrix deposition. Additional details of the material are given in Ref. [19]. Flexural beam specimens that measured $50.8 \mathrm{~mm}$ (length) $\times 6.3 \mathrm{~mm}$ (width) $\times 2.8 \mathrm{~mm}$ (thickness) were irradiated. The length and the width directions were in parallel with the fiber axes. Approximately 11 to 12 fabric planes were accommodated in the thickness.

Neutron irradiation was performed in the flux trap facility of the HFIR. The nominal irradiation temperatures were 573,773 , and $1073 \mathrm{~K}$. The actual irradiation temperatures were determined by the post-irradiation annealing of SiC temperature monitors [27]. The irradiation conditions are listed in Table 1 . The highest fast neutron fluences $(\mathrm{E}>0.1 \mathrm{MeV})$ achieved were $\sim 7.1, \sim 7.4$, and $\sim 7.1 \times 10^{26} \mathrm{n} / \mathrm{m}^{2}$ at respective temperatures. Assuming an equivalence of $1 \times 10^{25} \mathrm{n} / \mathrm{m}^{2}$ with $1 \mathrm{dpa}$ in $\mathrm{SiC}$ with the neutron spectrum in the HFIR target position, these fluences correspond with doses of $\sim 71$ to $\sim 74 \mathrm{dpa}$. 
Table 1. Irradiation conditions for Hi-Nicalon Type S, CVI SiC-matrix composites evaluated in this work. Actual irradiation temperatures were determined by measurement of swelling annealing with dilatometry

\begin{tabular}{cccc}
\hline Capsule ID & Dose [dpa] & $\begin{array}{c}\text { Design } \\
\text { temperature }[\mathrm{K}]\end{array}$ & $\begin{array}{c}\text { Actual irradiation } \\
\text { temperature [K] }\end{array}$ \\
\hline L3073 & 40.0 & 1073 & $1073 \pm 100^{*}$ \\
K0503 & 70.9 & 1073 & $1073 \pm 25$ \\
L3056 & 40.0 & 773 & $873 \pm 25$ \\
L3058 & 73.7 & 773 & $773 \pm 25$ \\
L3044 & 37.5 & 573 & $673 \pm 25$ \\
L3057 & 39.2 & 573 & $598 \pm 25$ \\
L3045 & 70.5 & 573 & $573 \pm 25$ \\
\hline
\end{tabular}

*Thermometry results are unavailable.

Following capsule disassembly and specimen shipment to the Low Activation Materials Development and Analysis laboratory at ORNL, the irradiated specimens were visually inspected. A slight metallic deposition was noted on one side of all specimens that had been irradiated at $773 \mathrm{~K}$ or higher. The metal is suspected to be chromium that was transferred from the specimen holder made of $\mathrm{V}-4 \mathrm{Cr}-4 \mathrm{Ti}$. The other sides of specimens that had been irradiated at $773 \mathrm{~K}$ showed periodical metallic deposition corresponding to the locations that were in contact with metallic springs that were used to ensure good thermal contact between specimens and specimen holder. When the capsules were built for irradiation at 573 and $773 \mathrm{~K}$, springs made of 304 stainless steel were accidentally used; thus the deposit is believed to have been transferred from the stainless steel. On the inner surfaces of the specimens irradiated at $1073 \mathrm{~K}$, for which molybdenum springs were used, no clear imprint of spring contacts was found.

Following the inspection, the specimen dimensions were measured with a caliper. Swelling was determined based on the length change, assuming an isotropy of swelling, because of anticipated relatively large errors in measurements in other dimensions. The Young's modulus was then determined by the impulse excitation and vibration method using the Grindosonic instrument following ASTM Standard C1259-08.

After completion of the impulse modulus measurement, each beam specimen was machined with a low-speed diamond saw into smaller specimens: $1 / 4$ size flexural beams $(\sim 25 \times \sim 6.3 \times \sim 1.2 \mathrm{~mm})$ or $1 / 8$ size flexural beams $(\sim 25 \times \sim 3.0 \times \sim 1.2 \mathrm{~mm})$ and thermal diffusivity coupons that measured $\sim 6 \times \sim 6 \times \sim 1.2 \mathrm{~mm}$. One of the $1 / 4$ or $1 / 8$ size beams in each irradiation condition was used for testing with dilatometry, using a Netzsch DIL $402 \mathrm{CD}$ dilatometer, up to $1673 \mathrm{~K}$ at a ramp rate of $2 \mathrm{~K} / \mathrm{min}$. The temperature of irradiation was analyzed using the data from dilatometry.

Thermal diffusivity was measured by the flash method at room temperature. A Netzsch LFA447 xenon flash diffusivity instrument was used. Typically, three replicate specimens were measured for each irradiation condition. Thermal conductivity was calculated using the measured thermal diffusivity averaged over five shots; bulk density of individual 
coupon specimens; and a literature value of specific heat for $\mathrm{SiC}$ [2]. In addition to these machined coupon samples, disc specimens of the identical material that had previously been measured after irradiation in the same HFIR facility were analyzed. These disc specimens were $\sim 6 \mathrm{~mm}$ in diameter and $\sim 4 \mathrm{~mm}$ in thickness and were irradiated at 473 to $1073 \mathrm{~K}$ to a dose range of 0.001 to $4.3 \mathrm{dpa}$.

The $1 / 4$ and $1 / 8$ size miniature flexural beam specimens were tested for strength at room temperature in a 4 point-1/4 point configuration, with a support span of $20 \mathrm{~mm}$, a load span of $10 \mathrm{~mm}$, and a crosshead speed of $0.5 \mathrm{~mm} / \mathrm{min}$, following the general guidelines of ASTM C1341-06. Three and six replicate specimens were tested with the 1/4 size and the $1 / 8$ size, respectively, for individual irradiation conditions. The $5 \%$ offset tangent modulus method was used to determine the PLS. The fracture surfaces were examined with a Hitachi S4700 scanning electron microscope.

\section{Results}

\section{Swelling}

As stated earlier, swelling of the composite was determined based on the specimen length change under an assumption of isotropy in swelling. An attempt to determine swelling using all three dimensions resulted in an unacceptable magnitude of data scatter due primarily to the limited measurement accuracy for pre-irradiation dimensions. The accuracy for length measurement also suffered relatively poor flatness and parallelism of the two faces perpendicular to the length, resulting in a significant scatter, as represented by the vertical error bars in Figure 1. However, the swelling values obtained in the current work fell within the literature data band for low- to medium-dose-irradiated similar composites and chemical vapor-deposited high-purity monolithic SiC. 


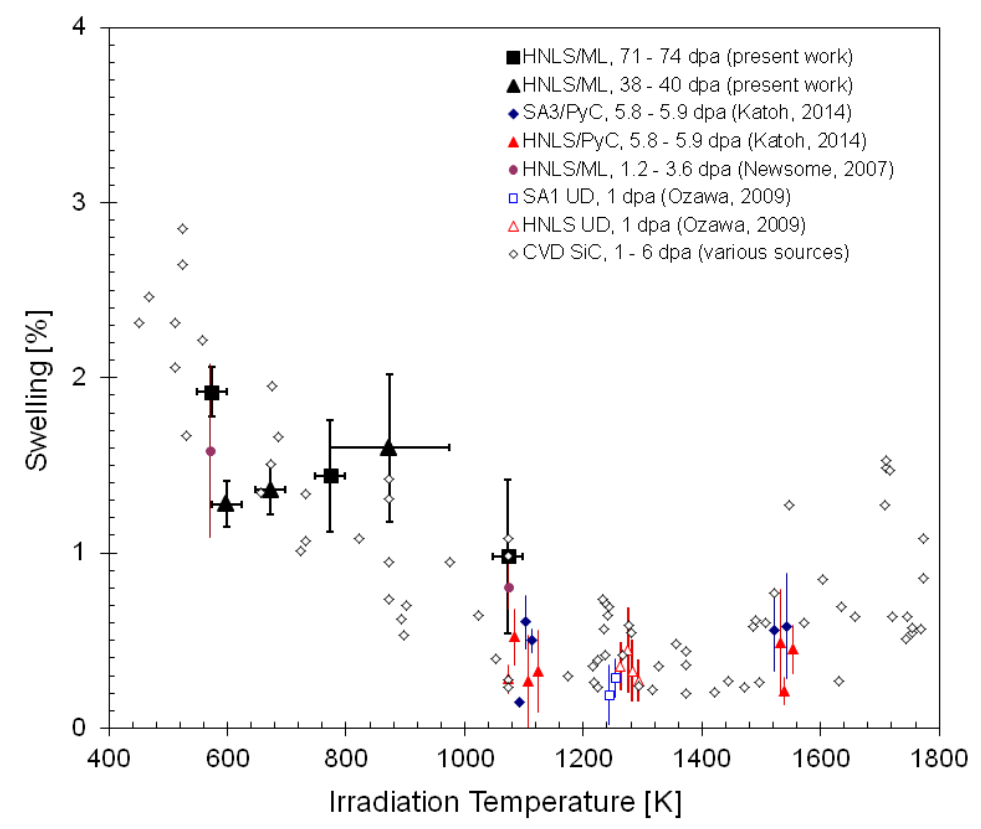

Figure 1. Swelling of Hi-Nicalon Type S, CVI SiC-matrix composites plotted against irradiation temperature. Literature data for nuclear-grade CVI SiC-matrix composites are shown together. Vertical error bars indicate \pm 1 standard deviation for measured swelling. Horizontal error bars indicate ranges for estimated uncertainty in irradiation temperatures. (Abbreviations in legend-HNLS: Hi-Nicalon Type S fiber; SA3: Tyranno-SA3 fiber; SA1: Tyranno-SA1 fiber; ML: PyC/SiC multilayer interphase; PyC: pyrocarbon interphase; UD: unidirectional composite; CVD SIC: chemical vapor-deposited $\mathrm{SiC}$ ).

\section{Thermal expansion and swelling recovery}

The specimen length changes during heating to $1673 \mathrm{~K}$ followed by cooling down to room temperature are shown in Figure 2. The post-irradiation coefficient of thermal expansion (CTE) appeared nearly identical with the unirradiated CTE (presented for very similar materials in Ref. [13]) up to the irradiation temperature, even at this high dose.

A clear exhibition of swelling recovery onset is noticed at near the nominal irradiation temperature in the heating CTE plot. This result is known to be due to the thermal recovery of certain irradiation-produced defects, and the temperature at which the heating CTE curve starts to deviate from the cooling CTE curve is believed to correspond to the temperature of irradiation toward the end of irradiation (for example, Ref. [28]). The present result demonstrates that this post-irradiation thermometry technique may be used for a nuclear-grade $\mathrm{SiC}$ composite sample up to doses of at least $70 \mathrm{dpa}$ in a temperature range of 573 to $1073 \mathrm{~K}$. Note that the apparent bending in the linear strain plot during heating in Figure 2 does not correctly indicate the irradiation temperature [29], which should be closer to the temperature at which the instantaneous CTE curve starts to deviate from the cooling curve.

It is shown that the thermal recovery of defects contributing to swelling ceases in the 1400-1600 K range for the specimens irradiated at 573 and $773 \mathrm{~K}$; whereas the $1073 \mathrm{~K}$ - 
irradiated specimen shows continued annealing of swelling throughout the same temperature range. Moreover, the thermal strain plots indicate that the irradiation swelling had not fully subsided after annealing to $1673 \mathrm{~K}$. For the $573 \mathrm{~K}$-irradiated specimen, the recovery of linear swelling was $0.32 \%$, or about one half the as-irradiated linear swelling. For the 773 and $1073 \mathrm{~K}$ irradiation cases, the linear swelling recovered by 0.19 and $0.12 \%$, respectively, accounting for approximately $40 \%$ of the as-irradiated linear swelling. These results imply that the very high-temperature recovery stages take place at $>1573 \mathrm{~K}$ for all irradiation temperatures in this research, as barely seen in the bending of heating strain curves at $\sim 1600 \mathrm{~K}$. The incomplete swelling recovery at $1673 \mathrm{~K}$ is contrary to the observation by Yano et al., who report complete recovery of swelling at $1673 \mathrm{~K}$ for reaction-bonded $\mathrm{SiC}$ irradiated to a significantly higher dose of $1.9 \times 10^{27} \mathrm{n} / \mathrm{m}^{2}(\mathrm{E}>$ $0.1 \mathrm{MeV}$ ) [30].

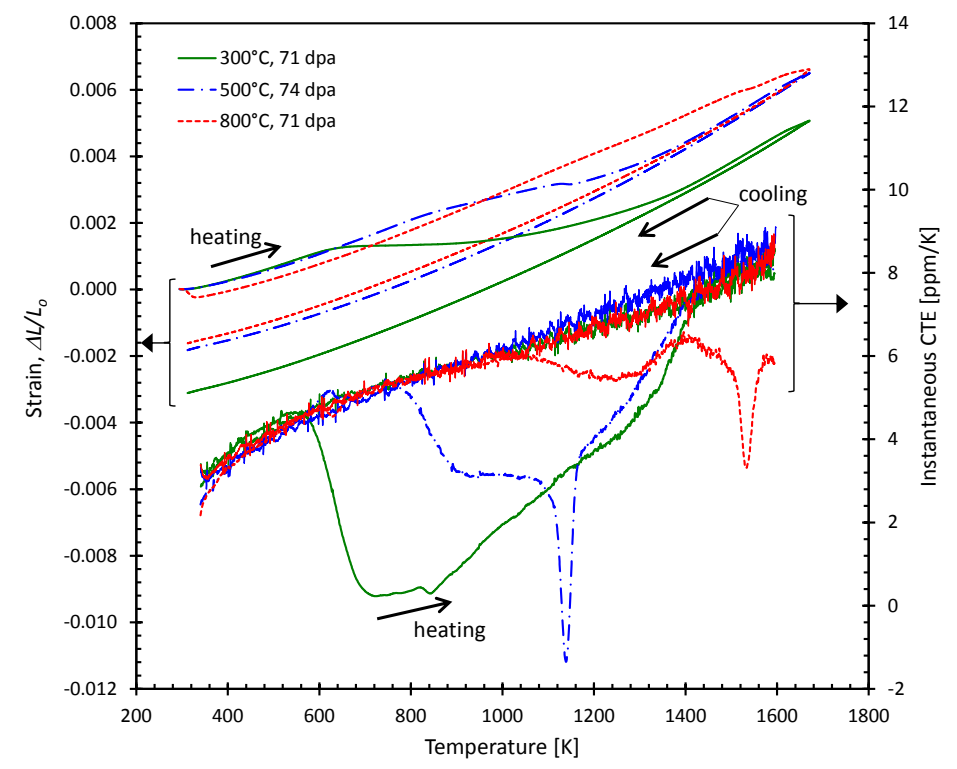

Figure 2. Dilatometry plots for irradiated Hi-Nicalon Type S, CVI SiC-matrix composites during heating and cooling sequences. Recovery of irradiation strain (swelling) is clearly observed starting at the temperatures of irradiation.

\section{Thermal conductivity}

The results of the thermal conductivity measurements are summarized in Table 2 . As is apparent from the relatively large standard deviations, the measured thermal diffusivity presented significant specimen-to-specimen variation arising from the small specimen geometry $\left(\sim 6 \times 6 \mathrm{~mm}^{2}\right)$ compared with the weave unit dimensions of $\sim 1.6 \mathrm{~mm}$ per thread. The radiation defect thermal resistivity, $\mathrm{Krd}^{-1}$, is defined by

$$
\mathrm{K}_{\mathrm{rd}}{ }^{-1}=\mathrm{K}_{0}^{-1}-\mathrm{K}_{\text {irr }}{ }^{-1}
$$


where $K_{0}$ and $K_{i r r}$ represent the unirradiated and irradiated thermal conductivity, respectively [31]. Here $K_{0}$ is a function of measurement temperature, whereas $K_{r d}$ is a function of irradiation temperature but is not very sensitive to the measurement temperature. Using Eq. (1), the general temperature dependence of $K_{0}$ in Ref. [13], and the $K_{r d}$ values derived in this work, the thermal conductivity of the irradiated materials at the irradiation temperature can be estimated as shown in Table 2.

Table 2. Result of room-temperature thermal conductivity parameter determination and estimated thermal conductivity at temperature of irradiation. Note that 20 to $30 \%$ errors are anticipated for radiation defect thermal resistivity and thermal conductivity at irradiation temperature

\begin{tabular}{ccccc}
\hline $\begin{array}{c}\text { Irradiation } \\
\text { condition }\end{array}$ & $\begin{array}{c}\text { Test } \\
\text { population }\end{array}$ & $\begin{array}{c}\text { RTa thermal } \\
\text { conductivity } \\
{[\mathrm{W} / \mathrm{m}-\mathrm{K}]}\end{array}$ & $\begin{array}{c}\text { Radiation defect } \\
\text { thermal } \\
\text { resistivity } \\
{[\mathrm{m} \cdot \mathrm{K} / \mathrm{W}]}\end{array}$ & $\begin{array}{c}\text { Thermal } \\
\text { conductivity at } \\
\text { irradiation } \\
\text { temperature } \\
{[\mathrm{W} / \mathrm{m} \cdot \mathrm{K}]}\end{array}$ \\
\hline Unirradiated & 4 & $16.3(5.6)^{\mathrm{b}}$ & - & - \\
$1073 \mathrm{~K}, 71 \mathrm{dpa}$ & 3 & $4.24(0.87)$ & 0.17 & 2.61 \\
$773 \mathrm{~K}, 74 \mathrm{dpa}$ & 3 & $1.21(0.23)$ & 0.76 & 1.07 \\
$573 \mathrm{~K}, 71 \mathrm{dpa}$ & 2 & $1.17(0.31)$ & 0.79 & 1.06 \\
\hline
\end{tabular}

a) Room temperature.

b) Numbers in parentheses indicate one standard deviation.

c) Estimated. See text for details.

Flexural strength and Young's modulus

The unirradiated specimens exhibited typical flexural behavior for continuous fiber composites with a high-modulus brittle matrix and high-modulus ceramic fibers, as shown in Figure 3 (a). The average ultimate flexural stress (UFS) was $335 \mathrm{MPa}$, which appears to be somewhat weaker than the data from testing using larger specimens $[19,23]$. Such a detrimental effect of small specimen thickness on flexural strength has been reported for similar materials. The PLS was around $180 \mathrm{MPa}$, beyond which a significant nonlinear load increase was observed. A complete failure occurred significantly after the sudden load drop following the load maximum, as is typical for these materials. The flexural tangent modulus, $\sim 168 \mathrm{GPa}$ as determined by the slope of the linear segment of the stress-strain plot, appeared significantly lower than the sonic modulus of $\sim 212 \mathrm{GPa}$ as determined by the impulse excitation and vibration method. Such a discrepancy is commonly observed in ceramic matrix composites and is speculated to be due to the differences in strain during testing [13]. The results of the flexural test and sonic modulus measurement are summarized in Table 3. 

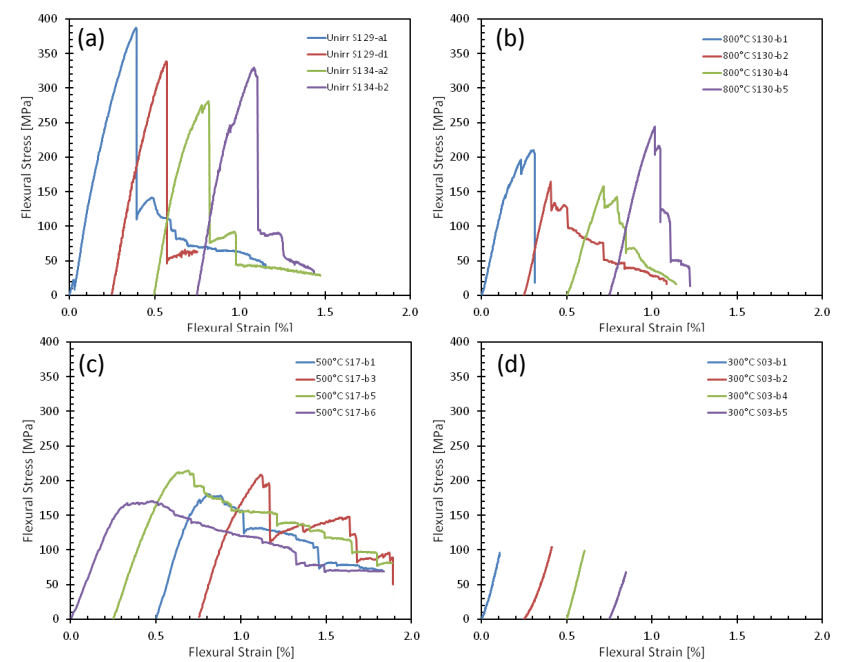

Figure 3. Flexural stress-strain properties of Hi-Nicalon Type S, CVI SiC-matrix composites in unirradiated condition (a) and after irradiation to $71-74 \mathrm{dpa}$ at $800^{\circ} \mathrm{C}$ (b), $500^{\circ} \mathrm{C}(\mathrm{c})$, and $300^{\circ} \mathrm{C}(\mathrm{d})$. Four representative curves were chosen from each condition, with specimen identifiers shown in legends.

The effect of irradiation on the flexural behavior appeared substantial, ranging from reduced strength after 1073 or $773 \mathrm{~K}$ irradiation to severe embrittlement after $573 \mathrm{~K}$ irradiation. After the $1073 \mathrm{~K}$ irradiation, the UFS decreased by $\sim 40 \%$, whereas the shape of the stress-strain curves, the PLS, and the sonic modulus were retained at the preirradiation levels. The flexural tangent modulus experienced only a minor decrease. The modulus of toughness decreased by about one-half, reflecting the UFS decrease.

The effects of $773 \mathrm{~K}$ irradiation on the flexural properties were more obvious, with a major modification in the stress-strain shape due to the significant reduction in UFS, a lack of sudden load drop right after the load maximum, and significant increase in failure strain. The extended failure strain resulted in a significant increase in the modulus of toughness despite the major UFS drop of $\sim 40 \%$. Unlike in the $1073 \mathrm{~K}$ irradiation case, the PLS decreased by a significant fraction of $\sim 30 \%$. Both sonic and flexural tangent moduli decreased to the greatest extent, by 30 to $40 \%$, among the three irradiation temperatures.

The $573 \mathrm{~K}$ irradiation resulted in a catastrophic losses of strength and toughness, as is obvious in the stress-strain plot, with absolutely no nonlinear behavior followed by failure at an average flexural strength of merely $91 \mathrm{MPa}$. The modulus of toughness was reduced to $1 / 20$ of the pre-irradiation value. Interestingly, the sonic and flexural tangent moduli decreases were less significant than for the $773 \mathrm{~K}$-irradiated specimens.

Table 3. Summary of flexural and elastic properties

\begin{tabular}{cccccccc}
\hline $\begin{array}{c}\text { Irradiation } \\
\text { condition }\end{array}$ & $\begin{array}{c}\text { Specimen } \\
\text { size }\end{array}$ & $\begin{array}{c}\text { Test } \\
\text { population }\end{array}$ & $\begin{array}{c}\text { Proportional } \\
\text { limit stress } \\
{[\mathrm{MPa}]}\end{array}$ & $\begin{array}{c}\text { Ultimate } \\
\text { flexural } \\
\text { stress } \\
{[\mathrm{MPa}]}\end{array}$ & $\begin{array}{c}\text { Modulus of } \\
\text { toughness } \\
\left.[\mathrm{M}] / \mathrm{m}^{3}\right]\end{array}$ & $\begin{array}{c}\text { Flexural } \\
\text { tangent } \\
\text { modulus } \\
{[\mathrm{GPa}]}\end{array}$ & $\begin{array}{c}\text { Dynamic } \\
\text { Young's } \\
\text { modulus } \\
{[\mathrm{GPa}]}\end{array}$ \\
\hline $\begin{array}{c}\text { Unirradiated } \\
1073 \mathrm{~K},\end{array}$ & $1 / 4$ & 8 & $317(27 \mathrm{a})$ & $444(34)$ & $\mathrm{n} / \mathrm{m}^{\mathrm{c}}$ & $\mathrm{n} / \mathrm{m}$ & $212(10)$ \\
$41 \mathrm{dpa}^{\mathrm{d}}$ & $1 / 4$ & 7 & $330(20)$ & $461(48)$ & $\mathrm{n} / \mathrm{m}$ & $\mathrm{n} / \mathrm{m}$ & $210(8)$
\end{tabular}




\begin{tabular}{cccccccc}
$873 \mathrm{~K}, 40 \mathrm{dpa}$ & $1 / 4$ & 2 & $277(30)$ & $304(43)$ & $\mathrm{n} / \mathrm{m}$ & $\mathrm{n} / \mathrm{m}$ & $213(2)$ \\
$673 \mathrm{~K}, 38 \mathrm{dpa}$ & $1 / 4$ & 2 & $152(27)$ & $152(27)$ & $\mathrm{n} / \mathrm{m}$ & $\mathrm{n} / \mathrm{m}$ & $192(8)$ \\
$598 \mathrm{~K}, 39 \mathrm{dpa}$ & $1 / 4$ & 2 & $270(17)$ & $297(24)$ & $\mathrm{n} / \mathrm{m}$ & $\mathrm{n} / \mathrm{m}$ & $190(2)$ \\
\hline Unirradiated & $1 / 8$ & 8 & $181(40)$ & $335(66)$ & $1.01(0.32)$ & $168(17)$ & $212(10)$ \\
$1073 \mathrm{~K}, 71 \mathrm{dpa}$ & $1 / 8$ & 6 & $181(47)$ & $204(50)$ & $0.49(0.07)$ & $148(23)$ & $210(4)$ \\
$773 \mathrm{~K}, 74 \mathrm{dpa}$ & $1 / 8$ & 6 & $128(13)$ & $202(34)$ & $1.80(0.40)$ & $100(12)$ & $156(1)$ \\
$573 \mathrm{~K}, 71 \mathrm{dpa}$ & $1 / 8$ & 6 & $91(21)$ & $91(21)$ & $0.05(0.02)$ & $114(22)$ & $192(2)$ \\
\hline
\end{tabular}

a) Numbers in parentheses indicate one standard deviation.

b) Dynamic Young's modulus was determined using two full-size specimens for each irradiation condition.

c) Not measured.

d) Previously reported in Ref. [23].

Figure 4 presents the fracture surfaces near the tensile faces of the flexurally failed composite specimens. The unirradiated fracture surface is typical of this material, showing very short fiber pullouts. The $1073 \mathrm{~K}$ irradiation did not impose noticeable changes in the fracture surface, showing the same short fiber pullout. The fiber fracture surface also looks similar to the unirradiated one, showing a river pattern originating from the relatively unclear fracture mirror.

Longer fiber pullouts are generally observed in the fracture surface of the $773 \mathrm{~K}$ irradiated specimen, corresponding with the extensive nonlinear behavior during the flexural tests. However, unlike in the unirradiated or $1073 \mathrm{~K}$-irradiated cases, the fiber fracture surfaces do not show the obvious river patterns but rather frequent flat and smooth fractures. As expected, the fracture surface of the $573 \mathrm{~K}$-irradiated composite showed a major change with practically no fiber pullout. The fiber fracture surfaces appeared entirely plain with no river patterns at all, clearly indicating major degradation of Hi-Nicalon Type S fibers in this irradiation condition. 

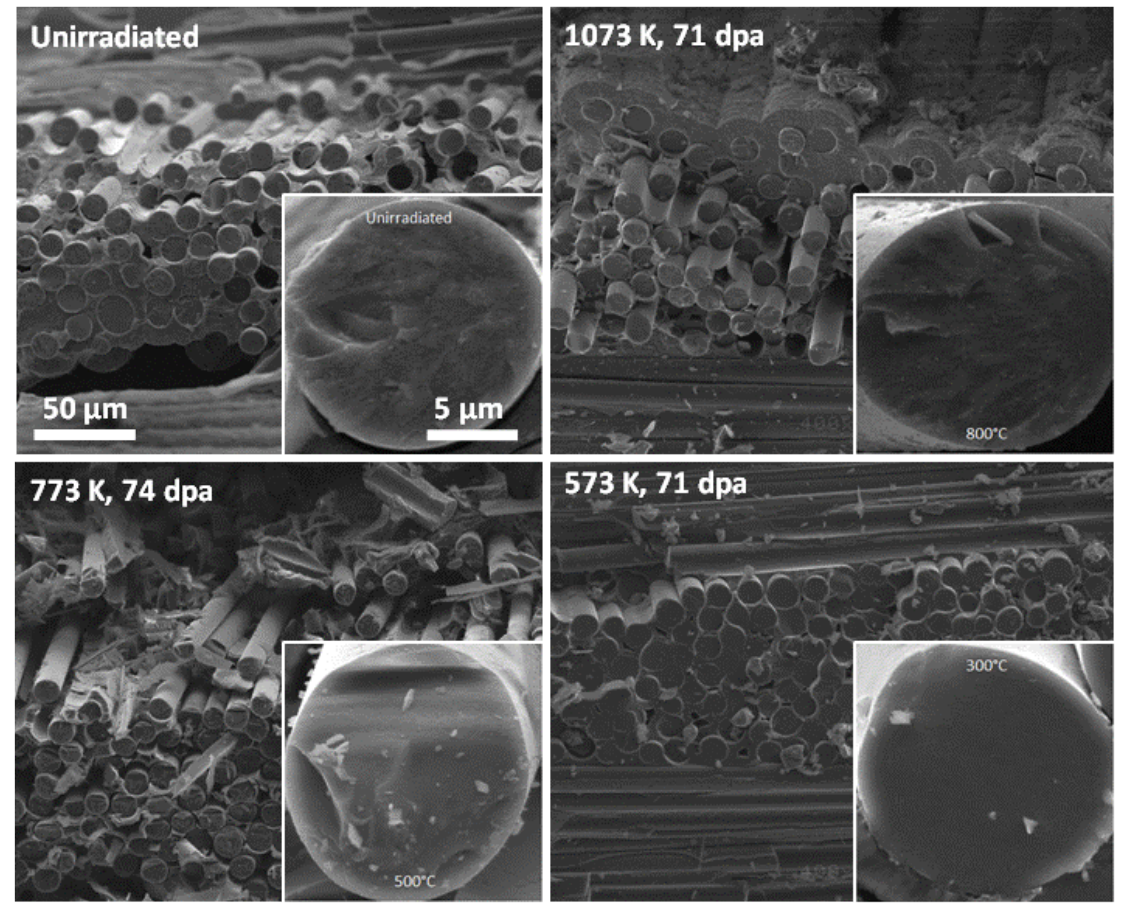

Figure 4. Scanning electron images of fracture surfaces of Hi-Nicalon Type S, CVI SiC-matrix composites in unirradiated and irradiated conditions. Insets show close-up images of typical fiber fracture surfaces.

\section{Discussion}

\section{Dose dependence}

Since some of the composite properties seem to progressively evolve in the high-dose regime, while other properties seem to remain saturated, it is useful to discuss the dose dependence of properties determined in this work. Previous reports have shown that swelling, thermal conductivity change, and elastic modulus change occur rapidly after the irradiation starts and then quickly saturate at around or below $1 \mathrm{dpa}$. Magnitudes of swelling determined in the present work, though involving substantial measurement errors, indicate continued saturation or at least no significant progressive increase as the dose increases from $\sim 1$ to $>70 \mathrm{dpa}$, as plotted in Figure 5 against dose. 


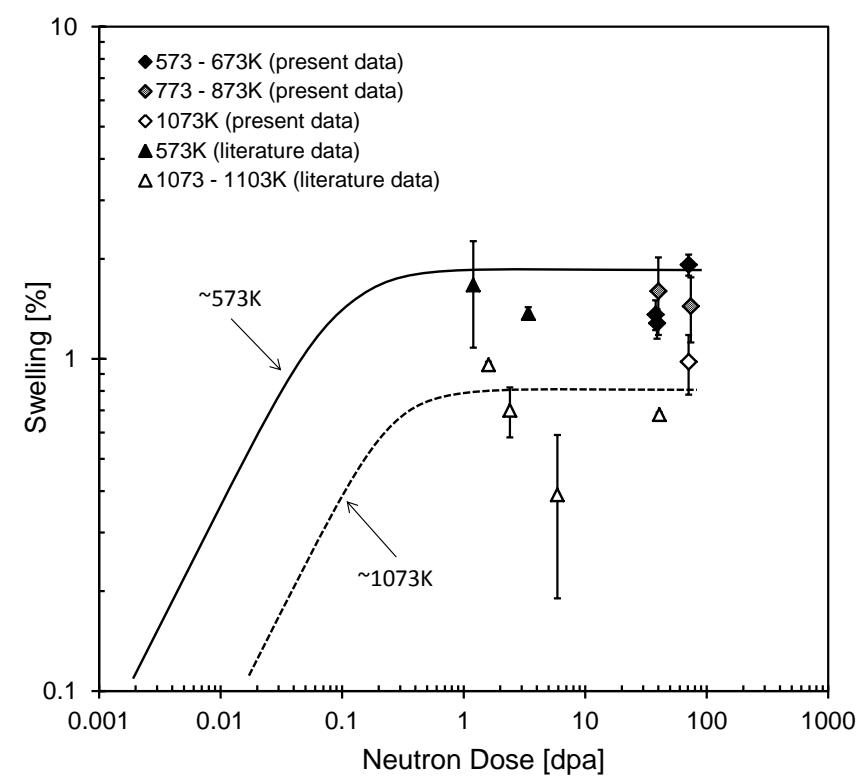

Figure 5. Neutron dose dependence of swelling for Hi-Nicalon Type-S, CVI SiC-matrix composite. Error bars indicate \pm 1 standard deviations. Literature data were taken from Refs. [13, $19,22]$.

Similar to swelling, the irradiation-induced thermal conductivity changes remain saturated, as is obvious in the plot of irradiation defect thermal resistivity against dose in Figure 6. In other words, the linear relationship between swelling and irradiation defect thermal resistivity that was found for high-purity monolithic $\mathrm{SiC}$ seemingly is also applicable to nuclear-grade $\mathrm{SiC}$ composites up to the high-dose regime in the temperature range of the current study.

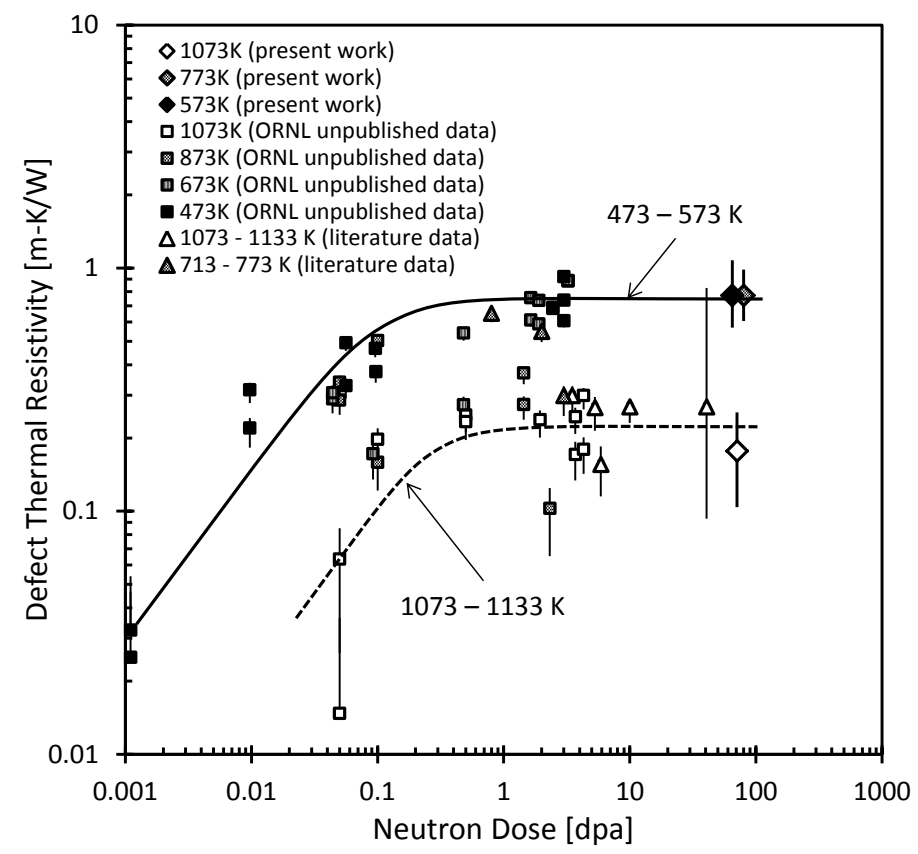

Figure 6. Neutron dose dependent evolution of through-thickness defect thermal resistivity for Hi-Nicalon Type S, CVI SiC-matrix composite. Error bars indicate likely ranges of uncertainty 
estimated from standard deviations for unirradiated and irradiated thermal conductivity data. Literature data were taken from Ref. [19, 22, 23].

The Young's modulus of crystalline bulk $\mathrm{SiC}$ is known to undergo a slight decrease followed by a saturation during irradiation, corresponding with the lattice swelling [2]. Composite materials consisting of crystalline $\mathrm{SiC}$ are therefore anticipated, and in fact reported, to behave in a similar manner [13]. However, at a dose level exceeding $70 \mathrm{dpa}$, the composite Young's modulus did not stay saturated but instead exhibited a declining trend at $773 \mathrm{~K}$ or lower temperatures, implying a progressive high-dose irradiation effect commencing in a dose range between 40 and 70 dpa (Figure 7). In other words, the correlations between a Young's modulus change with swelling and a thermal conductivity decrease are no longer maintained after 40 dpa is achieved at irradiation temperatures below $773 \mathrm{~K}$; this finding indicates that the modulus decrease is not due to the lattice expansion associated with point defect accumulation. It is speculated that the declining Young's modulus is related to degradation of the fiber-matrix interface and possibly the fibers, as discussed below.

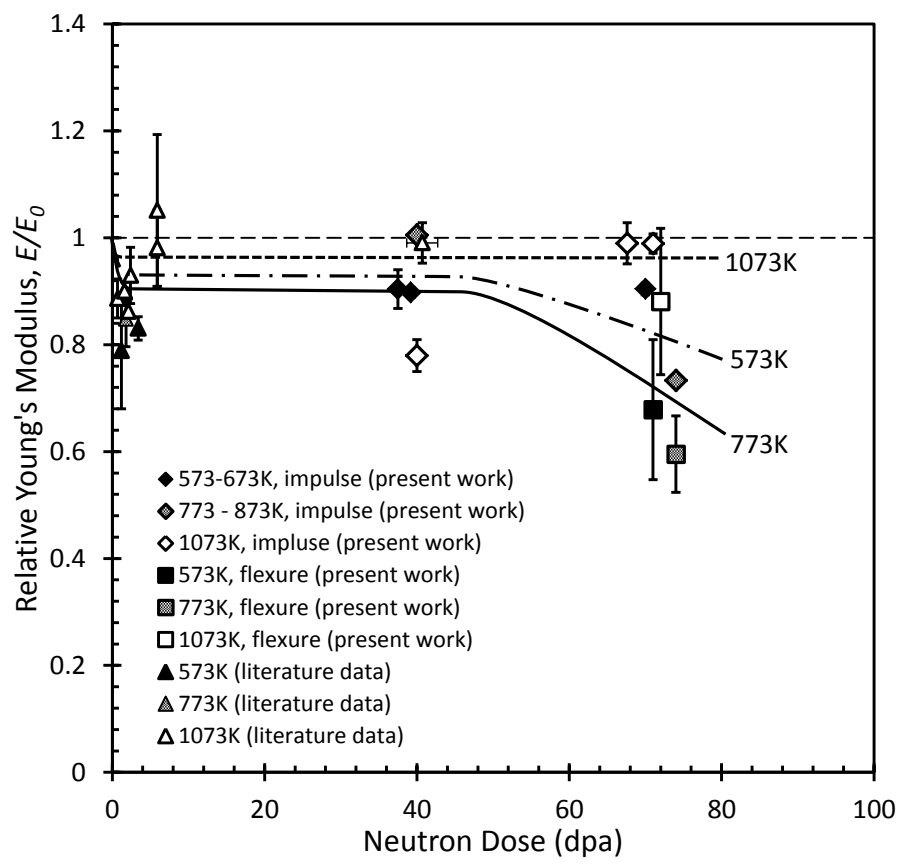

Figure 7. Neutron dose dependence of dynamic Young's modulus for Hi-Nicalon Type S, CVI $\mathrm{SiC}$-matrix, $\mathrm{PyC} / \mathrm{SiC}$ multilayer interphase composite normalized to pre-irradiation values. Error bars indicate \pm 1 standard deviation. "Impulse" and "flexure" in the legend denote measurement by impulse excitation and vibration method and flexural tangent modulus, respectively. Literature data were taken from Refs. [13, 19, 22].

Mechanical properties, including flexural strength and toughness, underwent clear and significant degradation at $\sim 40$ dpa. Figure 8 and Figure 9 show dose-dependent evolutions of the flexural PLS and ultimate strength, respectively, normalized to the pre-irradiation values. 


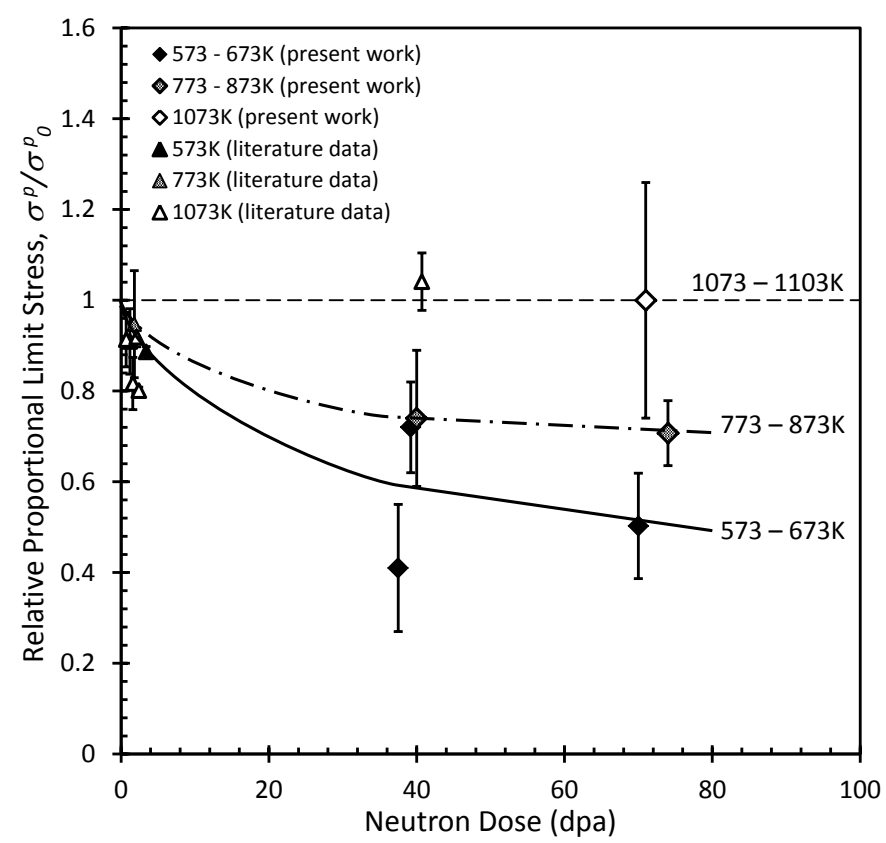

Figure 8. Neutron dose dependence of proportional limit flexural stress for Hi-Nicalon Type S, CVI SiC-matrix, PyC/SiC multilayer interphase composite normalized to pre-irradiation values. Error bars indicate \pm 1 standard deviations. Literature data were taken from Ref. [19, 23].

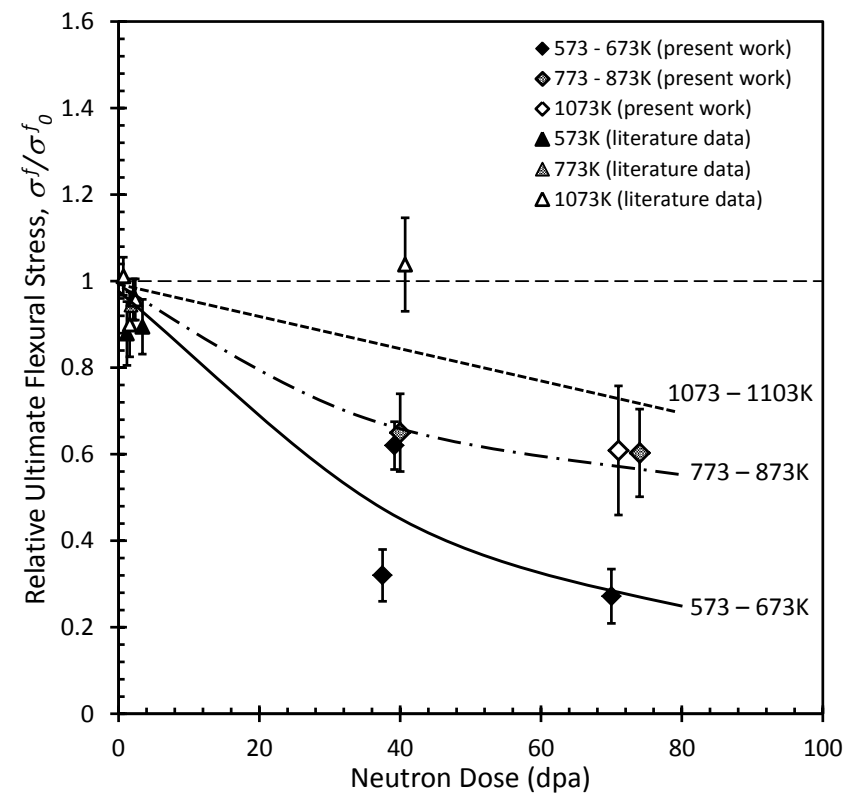

Figure 9. Neutron dose dependence of ultimate flexural stress for Hi-Nicalon Type S, CVI SiCmatrix, $\mathrm{PyC} / \mathrm{SiC}$ multilayer interphase composite normalized to pre-irradiation values. Error bars indicate \pm 1 standard deviations. Literature data were taken from Ref. [19, 23].

In the literature, strength properties of nuclear-grade $\mathrm{SiC}$ composites have been reported to remain nearly unchanged at low to medium fluence levels, such as $<10 \mathrm{dpa}$, in a broad temperature range $[13,15,18-22]$. However, the mechanical properties data are actually scarce if irradiation temperatures are limited to a relatively low range around 573 
$\mathrm{K}[18,19,22]$. The highest neutron dose previously reported for similar materials at $\sim 573 \mathrm{~K}$ is 6 dpa in Hinoki et al. [18], which finds no significant degradation in flexural PLS or ultimate strength for Hi-Nicalon Type S fiber, CVI SiC-matrix composite with a thicker PyC interphase. At a higher irradiation temperature of $1073 \mathrm{~K}$, Katoh et al. reported a lack of flexural properties degradation at a dose level of $\sim 41 \mathrm{dpa}$ [23]. Therefore, the strength degradation observed in the present work is a high-dose irradiation effect.

\section{Degradation mechanism}

The significant high-dose irradiation-induced degradation in UFS was observed at all temperatures with increasing magnitude as irradiation temperature dropped.

Theoretically, in ideal unidirectionally-reinforced composites, the ultimate tensile strength is determined solely by the statistical strength of the fibers [32]. Considering the theory, and the observed major decrease in UFS accompanied by the changes in fracture surfaces, there remains very little doubt that the Hi-Nicalon Type $S$ fiber underwent major degradation at high doses. The instability of the carbonaceous phase in the fiber was noted by a transmission electron microscopy analysis that was performed in companion research by Perez-Bergquist et al.[26] On the other hand, it is generally less clear whether and to what extent degradation of the fiber/matrix interface and the matrix have occurred. These questions are discussed later in this section in more detail for individual irradiation temperatures.

The $1073 \mathrm{~K}$ irradiation to $\sim 74 \mathrm{dpa}$ imposed the least significant effects on mechanical properties, practically not affecting the PLS and Young's modulus. The fact that PLS was retained at the pre-irradiation level implies no significant degradation in the matrix fracture toughness or interface mechanical properties $[32,33]$. The significant decrease in UFS indicates fiber strength degradation, a finding that is also supported by the reduced strain to composite failure. However, the sawtooth-like post-linear stress-strain behavior shown in Figure 3 (b), the presence of fiber pullouts on the composite fracture surface, and the unmodified fiber fracture surface imply that the fibers maintain a reasonable level of strength. The uncompromised irradiated Young's modulus indicates lack of substantial interface debonding or matrix microcracking. The lack of matrix microcracking damage is further supported by scanning electron microscopy observation of the polished crosssection [26] and the lack of a deviation in thermal conductivity from the saturated value that is not very low. Moreover, the interfacial characterization by Nozawa et al. [34] showed the unchanged debond shear stress of the frictional stress, implying no significant modification in the fiber/matrix interface. The stability of interfacial microstructures has been reported at this irradiation temperature [26]. Based on these observations, significant effects of $1073 \mathrm{~K}$ irradiation to $74 \mathrm{dpa}$ are limited to a moderate degree of fiber degradation.

After $773 \mathrm{~K}$ irradiation to $\sim 71 \mathrm{dpa}$, more significant effects on the composite mechanical properties were observed, including the reductions in PLS and Young's modulus and in UFS. The PLS decrease implies damage in the interface or the matrix or both, although severe fiber degradation can also contribute through the mitigated load sharing. The major decrease in the sonic Young's modulus implies the same. Lack of a progressive decrease in thermal conductivity supports that the damage is at the interface rather than in the matrix, because the fiber contribution to the through-thickness 
composite thermal conductivity is very limited in this material. Again, the substantially compromised UFS indicates significant fiber degradation. Modification of the fiber fracture surface strengthens the case. However, the observed increase in failure strain means both decreased fiber/matrix bonding and a moderate level of strength remaining in fibers. The interface characterization by Nozawa et al. [34] indicates severe reductions in both fiber/matrix debond stress and sliding stress, which is consistent with the previous interpretation. Considering the severity of the Young's modulus decrease, the interface damage likely involves partial debond. The conclusion is that moderate fiber degradation has occurred, and additional interface damage is likely. No conclusion can be drawn as to potential degradation of the matrix mechanical properties.

The effect of neutron irradiation at $573 \mathrm{~K}$ to $\sim 74 \mathrm{dpa}$ on the strength of this material is catastrophic. The complete loss of post-linear strain accompanied by a very major reduction in failure stress indicates severe degradation of fibers. The loss of fracture patterns from the fiber fracture surface and the observation of severe fiber chipping on the polished cross-section reported by Perez-Bergquist et al. [26] are evidence of severe fiber degradation. Since the thermal conductivity saturation has been maintained, and the polished cross-section did not show apparent cracks, matrix microcracking damage is extremely unlikely. However, this argument does not preclude the possible degradation of matrix strength. Given the lack of matrix microcracking damage, the significant reduction in sonic Young's modulus indicates significant interface mechanical damage, likely debond. Such fiber/matrix interfacial debond has been reported for this irradiation condition [26]. Nozawa et al. report a major reduction in fiber/matrix interfacial debond stress and a mild reduction in interfacial frictional stress. A recent ion irradiation experiment by Kondo et al. [35], showing a very significant differential swelling between the CVI SiC matrix and HiNicalon Type S fiber at $573 \mathrm{~K}$ and $100 \mathrm{dpa}$, implies the development of strong tensile stress across the interface during irradiation at this temperature. The lack of post-linear flexural behavior and the lack of fiber pullout even with significant interfacial degradation enhances the already strong case for a loss of fiber toughness. Overall, catastrophic fiber degradation and significant interface damage resulted from $573 \mathrm{~K}$ irradiation to $\sim 74 \mathrm{dpa}$.

\section{Conclusions}

A Hi-Nicalon Type S SiC fiber, CVI SiC-matrix composite with a PyC/SiC multilayer interphase was irradiated up to damage levels of $>70 \mathrm{dpa}$ at temperatures of 573,773 , and $1073 \mathrm{~K}$. The following important results were obtained.

1. Swelling remained at the low-dose saturation levels for high-purity CVD $\mathrm{SiC}$ for a given irradiation temperature. Thermal annealing of swelling, as examined by dilatometry, clearly indicated the temperatures of irradiation. Only partial recovery of swelling was achieved at $1673 \mathrm{~K}$.

1) The thermal conductivity decrease remained at the low-dose saturation levels for the identical material for a given irradiation temperature.

2. The Young's modulus started to deviate from the low-dose saturation levels (or the pre-irradiation level) during the $\sim 40-\sim 70$ dpa interval under irradiation at or below $773 \mathrm{~K}$. This finding is attributed to mechanical damage to the interface.

2) Flexural strength properties were significantly modified at $>70$ dpa at all irradiation temperatures examined. There were an observed UFS decrease at all temperatures, 
PLS and Young's modulus decreases at $<773 \mathrm{~K}$, and severe embrittlement and loss of strength at $573 \mathrm{~K}$.

Based on observations in the present work and the findings in companion works, the following conclusions are drawn for the effects of high-dose irradiation on the constitutive properties of this composite system.

$1073 \mathrm{~K}, 74 \mathrm{dpa}$ : Irradiation effects in addition to those for specimens saturated at a low dose are limited to the moderate degradation of fiber strength.

$773 \mathrm{~K}, 71 \mathrm{dpa}$ : In addition to the moderate degradation of fiber strength, significant interface damage probably emerged. This damage was already significant at a dose level of $\sim 40$ dpa. Mechanical properties degradation of the matrix was not confirmed.

$573 K, 74$ dpa: Very severe degradation of fiber strength and significant interface damage were confirmed. These damage effects were already significant at a dose level of $\sim 40 \mathrm{dpa}$. Mechanical properties degradation of the matrix was not confirmed.

Finally, the observed detrimental effects of neutron irradiation on the composite material are to a large extent attributed to the high-dose radiation instability of Hi-Nicalon Type S fiber. Future works will include attempts to identify the mechanism of the fiber degradation and to determine the high dose irradiation effects in SiC fibers with different microstructures.

\section{Acknowledgements}

The authors acknowledge A.M. Williams, P.S. Tedder, R.A. Meisner, and H. Wang for assistance in conducting experimental research, K.A. Terrani for technical review, and D.M Counce for editorial review. This research was sponsored by the Office of Fusion Energy Sciences, U.S. Department of Energy, and Japan Atomic Energy Agency under contracts DEAC05-000R22725 and NFE-10-02779, respectively, with UT-Battelle, LLC. Samples were irradiated in the High Flux Isotope Reactor, an Office of Science User Facility.

\section{References}

[1] R.J. Price, Properties of silicon carbide for nuclear fuel particle coatings, Nuclear Technology, 35 (1977) 320-336.

[2] L.L. Snead, T. Nozawa, Y. Katoh, T.S. Byun, S. Kondo, D.A. Petti, Handbook on SiC Properties for Fuel Performance Modeling, Journal of Nuclear Materials, 371 (2007) 329-377.

[3] Y. Katoh, L.L. Snead, I. Szlufarska, W.J. Weber, Radiation Effects in SiC for Nuclear Structural Applications, Current Opinion in Solid State \& Materials Science, 16 (2012) 143-152. [4] L.L. Snead, T. Nozawa, M. Ferraris, Y. Katoh, R. Shinavski, M. Sawan, Silicon carbide composites as fusion power reactor structural materials Journal of Nuclear Materials, 417 (2011) 330-339.

[5] A. Iveković, S. Novak, G. Dražić, D. Blagoeva, S.G.d. Vicente, Current status and prospects of $\mathrm{SiCf} / \mathrm{SiC}$ for fusion structural applications, Journal of the European Ceramic Society, 33 (2013) 1577-1589. 
[6] A.R. Raffray, R. Jones, G. Aiello, M. Billone, L. Giancarli, H. Golfier, A. Hasegawa, Y. Katoh, A. Kohyama, S. Nishio, B. Riccardi, M.S. Tillack, Design and material issues for high performance $\mathrm{SiCf} / \mathrm{SiC}$-based fusion power cores, Fusion Engineering and Design, 55 (2001) 5595.

[7] K. Yueh, K.A. Terrani, Silicon carbide composite for light water reactor fuel assembly applications, Journal of Nuclear Materials, 448 (2014) 380-388.

[8] R.J. Shinavski, T.Z. Engel, R. Battiste, R. Trejo, E. Lara-Curzio, Mechanical Performance and Design of $\mathrm{SiC} / \mathrm{SiC}$ for VHTR Control Rod Sheaths, Transactions of the American Nuclear Society, (2008).

[9] C. Sauder, Ceramic Matrix Composites: Nuclear applications, in: N.P. Bansal, J. Lamon (Eds.) Ceramic Matrix Composites: Materials, Modeling and Technology, Wiley, Hoboken, NJ, 2014, pp. 609-646.

[10] A.R. Bunsell, A. Piant, A review of the development of three generations of small diameter silicon carbide fibres, Journal of Materials Science, 41 (2006) 823-839.

[11] R. Naslain, Design, preparation and properties of non-oxide CMCs for application in engines and nuclear reactors: an overview, Composites Science and Technology, 64 (2004) 155170.

[12] Y. Katoh, A. Kohyama, T. Nozawa, M. Sato, $\mathrm{SiC} / \mathrm{SiC}$ composites through transient eutectic-phase route for fusion applications, Journal of Nuclear Materials, 329 (2004) 587-591. [13] Y. Katoh, K. Ozawa, C. Shih, T. Nozawa, R.J. Shinavski, A. Hasegawa, L.L. Snead, Continuous SiC Fiber, CVI SiC Matrix Composites for Nuclear Applications: Properties and Irradiation Effects, Journal of Nuclear Materials, 448 (2014) 448-476.

[14] T. Koyanagi, K. Ozawa, T. Hinoki, K. Shimoda, Y. Katoh, Effects of neutron irradiation on mechanical properties of silicon carbide composites fabricated by nano-infiltration and transient eutectic-phase process, Journal of Nuclear Materials, 448 (2014) 478-486.

[15] L.L. Snead, Y. Katoh, A. Kohyama, J.L. Bailey, N.L. Vaughn, R.A. Lowden, Evaluation of neutron irradiated near-stoichiometric silicon carbide fiber composites, Journal of Nuclear Materials, 283 (2000) 551-555.

[16] L.L. Snead, D. Steiner, S.J. Zinkle, Measurement of the effect of radiation damage to ceramic composite interfacial strength, Journal of Nuclear Materials, 191-194 (1992) 566-570. [17] Y. Katoh, A. Kohyama, L.L. Snead, T. Hinoki, A. Hasegawa, Neutron Tolerance of Advanced SiC-Fiber / CVI-SiC Composites, in: 19th IAEA Fusion Energy Conference, 2002, pp. FT/P1-03.

[18] T. Hinoki, L.L. Snead, Y. Katoh, A. Hasegawa, T. Nozawa, A. Kohyama, The effect of high dose/high temperature irradiation on high purity fibers and their silicon carbide composites, Journal of Nuclear Materials, 307 (2002) 1157-1162.

[19] G.A. Newsome, L.L. Snead, T. Hinoki, Y. Katoh, D. Peters, Evaluation of neutron irradiated silicon carbide and silicon carbide composites, Journal of Nuclear Materials, 371 (2007) 76-89.

[20] J.B.J. Hegeman, J.G. van der Laan, M. van Kranenburg, M. Jong, D.S. d'Hulst, P. ten Pierick, Mechanical and thermal properties of $\mathrm{SiCf} / \mathrm{SiC}$ composites irradiated with neutrons at high temperatures, Fusion Engineering and Design, 75-59 (2005) 789-793.

[21] K. Ozawa, T. Nozawa, Y. Katoh, T. Hinoki, A. Kohyama, Mechanical Properties and Microstructure of Advanced $\mathrm{SiC} / \mathrm{SiC}$ composites after Neutron Irradiation, Journal of Nuclear Materials, 367 (2007) 713-718. 
[22] Y. Katoh, L.L. Snead, T. Nozawa, S. Kondo, J.T. Busby, Thermophysical and Mechanical Properties of Near-Stoichiometric Fiber $\mathrm{CVI} \mathrm{SiC} / \mathrm{SiC}$ Composites after Neutron Irradiation at Elevated Temperatures, Journal of Nuclear Materials, 403 (2010) 48-61.

[23] Y. Katoh, T. Nozawa, L.L. Snead, K. Ozawa, H. Tanigawa, Stability of SiC and its Composites at High Neutron Fluence, Journal of Nuclear Materials, 417 (2011) 400-405. [24] Y. Katoh, T. Nozawa, L.L. Snead, T. Hinoki, Effect of Neutron Irradiation on Tensile Properties of Unidirectional Silicon Carbide Composites, Journal of Nuclear Materials, 367 (2007) 774-779.

[25] Y. Katoh, K. Ozawa, T. Hinoki, Y.B. Choi, L.L. Snead, A. Hasegawa, Mechanical Properties of Advanced SiC Fiber Composites Irradiated at Very High Temperatures, Journal of Nuclear Materials, 417 (2011) 416-420.

[26] A.G. Perez-Bergquist, T. Nozawa, C. Shih, K.J. Leonard, L.L. Snead, Y. Katoh, High Dose Neutron Irradiations of Hi-Nicalon Type S Silicon Carbide Composites, Part 1: Microstructural Evaluations, Journal of Nuclear Materials, (in press).

[27] L.L. Snead, A.M. Williams, A.L. Qualls, Revisiting the Use of SiC as a Post Irradiation Temperature Monitor, in: M.L. Grossbeck, T.D. Allen, R.G. Lot, A.S. Kumar (Eds.) The Effects of Radiation on Materials: 21st International Symposium, ASTM STP 1447, ASTM International, West Conshohocken, PA, 2003.

[28] R.J. Price, Annealing behavior of neutron-irradiated silicon carbide temperature monitors, Nuclear Technology, 16 (1972) 536-542.

[29] J.E. Palentine, THE CALIBRATION OF FAST REACTOR IRRADIATED SILICON CARBIDE TEMPERATURE MONITORS USING A LENGTH MEASUREMENT

TECHNIQUE Journal of Nuclear Materials, 92 (1980) 43-50.

[30] T. Yano, H. Miyazaki, M. Akiyoshi, T. Iseki, X-ray diffractometry and high-resolution electron microscopy of neutron-irradiated $\mathrm{SiC}$ to a fluence of $1.9 \times 1027 \mathrm{n} / \mathrm{m} 2$, Journal of Nuclear Materials, 253 (1998) 78-86.

[31] L.L. Snead, S.J. Zinkle, D.P. White, Thermal conductivity degradation of ceramic materials due to low temperature, low dose neutron irradiation, Journal of Nuclear Materials, 340 (2005)

187-202.

[32] A.G. Evans, J.-M. Domergue, E. Vagaggini, Methodology for relating the tensile constitutive behavior of ceramic-matrix composites to constituent properties, Journal of the American Ceramic Society, 77 (1994) 1425-1435.

[33] W.A. Curtin, Theory of mechanical properties of ceramic-matrix composites, Journal of the American Ceramic Society, 74 (1991) 2837-2845.

[34] T. Nozawa, P. Dou, K. Ozawa, L.L. Snead, H. Bei, Y. Katoh, H. Tanigawa, Strength and Microstructures of the Fiber/Matrix Interface of Neutron-Irradiated SiC/SiC Composites, in: 15th International Conference on Fusion Reactor Materials, Charleston, 2011.

[35] S. Kondo, T. Koyanagi, T. Hinoki, Irradiation creep of 3C-SiC and microstructural understanding of the underlying mechanisms, Journal of Nuclear Materials, (Accepted). 